\title{
EDITORIAL
}

\section{The Swiss Virtual Campus}
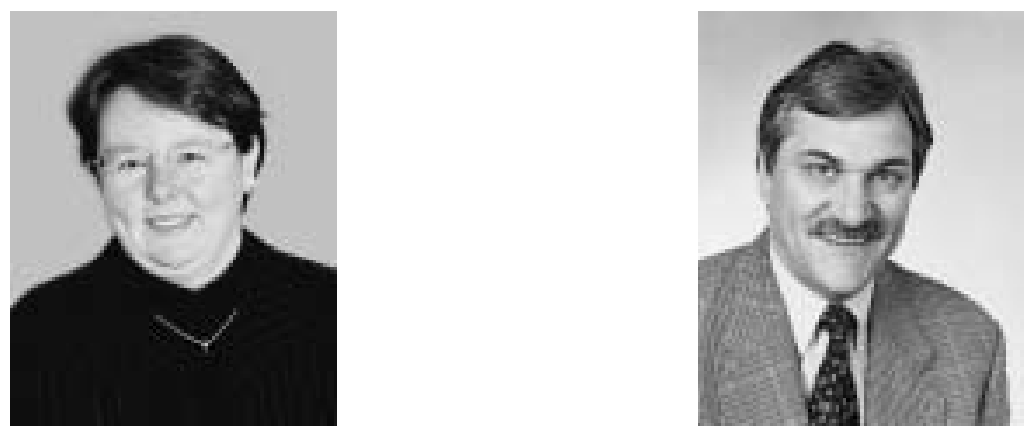

In 1993, informatics specialists showed a coffee pot at an English institute, declaring that via a new technology called the 'World Wide Web' it was now possible to check from anywhere in the world, 24 hours a day, how much coffee was available. A new technology that made us dream had been born. Now, only ten years later, this technology is not unusual anymore and it is broadly influencing our daily life. We regularly 'google' to find new acquaintances and if we encounter an unexpected problem, we perform a quick Internet search to obtain relevant information within minutes. An innovative additional application of the Internet, called 'e-learning', was identified as a attractive opportunity by the Rectors' Conference of the Swiss Universities (CRUS).

The CRUS considers the modernization of teaching to be one of the primary goals for the years to come. To work towards this challenging goal, the Swiss Virtual Campus, a Swiss federal program, was initiated in 2000. The goal of this four-year program is to promote and implement new information and communication technologies at universities and to develop Internet-based courses mainly for undergraduate students. The funding is provided in equal portions from federal and institutional sources. This approach promotes the integration of e-learning into existing curricula of Swiss universities rather than the creation of new virtual rival institutions.

Web-based methodologies offer fascinating opportunities not only for keeping up-to-date with the latest insights in natural science, but also teaching them to the next generation of students. There is an additional advantage. The complexity of the field requires studies that rely heavily on practical experiments. However, experiments are expensive and time consuming, making their simulation in a virtual environment a highly attractive proposition, especially since these experiments would be accessible via the Internet from anywhere in the world. In this special issue of CHIMIA we discuss how the presented SVC projects make use of the new media to the benefit of future generations of students in Chemistry, Pharmacy, Physics and Medicine in Switzerland.

The seven e-learning projects presented here provide a picture of what the term 'Swiss Virtual Campus' stands for, namely a virtual university space that includes not only cooperative projects on a national level supported by the Swiss Virtual Campus program, but also international cooperation ('Vernetztes Studium Chemie') and creative initiatives of the ETH Zürich.

Having completed an impressive takeoff phase, the Swiss Virtual Campus now plans to consolidate the current programs during the next funding period (2004 to 2007), in order to guarantee their sustainability. In addition, the development of new project networks and e-learning production centers at Swiss universities will be subsidized. We are grateful to the authors of the contributions to this special issue of CHIMIA, who have not only demonstrated that it is possible to produce state-of-the-art e-learning in Switzerland, but have also paved the way for new information and communication technologies in teaching science.<smiles>C1CCCCCC1</smiles><smiles>C1CCCCC1</smiles><smiles>CCCCCCC</smiles>

Dr. Cornelia Rizek-Pfister

Coordinator Swiss Virtual Campus Swiss University Conference Sennweg 2 $\mathrm{CH}-3012$ Bern

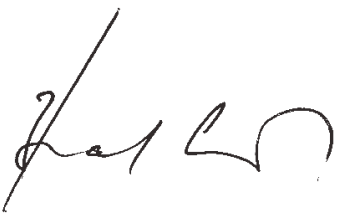

Prof. Dr. Beat Ernst

Institute of Molecular Pharmacy Pharmacenter, University of Basel Klingelbergstrasse 50 $\mathrm{CH}-4056$ Basel

It is with great pleasure and appreciation that the Editorial Board of CHIMIA expresses its warmest thanks to the coordinating guest editor Prof. Beat Ernst for his enormous effort in planning and collating the present most attractive selection of contributions on the topic of 'Swiss Virtual Campus'. 